\title{
Investigation of jarosite process tailing waste by means of raman and infrared spectroscopy
}

\section{Untersuchung des Abfallerzes des Jarosit-Prozesses durch Raman- und Infrarot-Spektroskopie}

\author{
M. Kerolli-Mustafa' ${ }^{1}$ I. Bačić ${ }^{2}$ L. Ćurković ${ }^{3}$
}

The aim of this work was to identify and characterize three samples of jarosite process tailing waste in Mitrovica, Kosovo, using Raman and Fourier transform infrared (FTIR) spectroscopy. The identification is made based on the assignment of bands in the Raman and FTIR spectra. Both Raman and FTIR spectra show the fundamental stretching and bending vibration mode of $\mathrm{SO}_{4}^{2-}, \mathrm{OH}^{-}$and $\mathrm{NH}_{4}^{+}$groups.

The results obtained by the means of Raman and infrared spectroscopy are compared with cited reference data in order to sum the analysis of vibrational spectra.

Keywords: Jarosite / Waste / Raman / Infrared / Spectroscopy

Schlüsselwörter: Jarosit / Abfall / Raman / Infrarot / Spektroskopie

\section{Introduction}

Worldwide, jarosite process is the most widely used techniques in the zinc industry. During this process Fe (III) compound of the type $\mathrm{MFe}_{3}\left(\mathrm{SO}_{4}\right)_{2}(\mathrm{OH})_{6}$, where $\mathrm{M}$ is usually monovalent $\mathrm{Na}^{+}$, $\mathrm{K}^{+}, \mathrm{NH}_{4}^{+}, \mathrm{H}_{3} \mathrm{O}^{+}, \mathrm{Ag}^{+}$or divalent cation such as $\mathrm{Pb}^{2+}$ is precipitating, and a huge amount of jarosite waste is released [1]. This jarosite waste contains high concentrations of toxic metals that may become a major environmental and ecological problem. This issue became a dramatic in Mitrovica (Kosovo) were 35 ha of the town has been covered by zinc smelter waste, situated very close to the residential area. Raman and infrared vibrational spectroscopy techniques are regarded as powerful techniques to characterise the minerals, natural jarosite and the jarosite released from the zinc smelter process. The recent study presents the means of these techniques to characterise the jarosite waste in Kosovo.

In general, the methods of the vibrational spectroscopy provide information about stretching and bending vibration that are coupled with variations in interatomic distances and angles. These methods can be used for identification of compounds as well. Raman and Infrared (FTIR) spectroscopy as complementary techniques are suitable for analysis of compounds of jarosite

${ }^{1}$ Faculty of Mining and Technology, University of Prishtina, Mitrovica, Kosovo

${ }^{2}$ Forensic Science Centre "Ivan Vucetic", Ministry of Interior of Republic of Croatia, Zagreb, Croatia

${ }^{3}$ Faculty of Mechanical Engineering and Naval Architecture, University of Zagreb, Zagreb, Croatia

Corresponding author: Mihone Kerolli-Mustafa, MA, Isa Boletini 10, 40000 Mitrovica, Kosovo

E-mail:mihone_k@hotmail.com mineral groups, either natural or synthetic, published in numerous studies [1-10]. Methods are sensitive to vibrational bonding modes of most functional groups in jarosite molecules $\left(\mathrm{OH}^{-}\right.$, $\mathrm{H}_{2} \mathrm{O}, \mathrm{H}_{3} \mathrm{O}^{+}, \mathrm{SO}_{4}^{2-}$ and $\left.\mathrm{Fe}-\mathrm{O}\right)$ that are particularly suitable for analysis of sulphates [2].

Sulphate anion in aqueous solution has $T_{d}$ symmetry which is characterized with four Raman bands originating from: symmetric $\left(v_{1}\right)$ and asymmetric $\left(v_{3}\right)$ stretching modes and symmetric $\left(v_{2}\right)$ and asymmetric $\left(v_{4}\right)$ bending modes $[1,3]$. However, symmetry of sulphate anion in crystal structures is reduced $\left(C_{3 \mathrm{v}}\right)$ leading to splitting of these modes. In accordance with the theory group in the spectra of jarosite six basic sulphate bands should occur [1, 3, 4]. Raman and FTIR spectra, except for the determination of group of minerals, can be used for identification of minerals and type of interlayer cation $\left(\mathrm{M}^{+}\right)$as well. In his study, Sasaki et al. reported about the relationship between the type of cation $\left(\mathrm{M}^{+}\right)$ and the position of some bands, as a consequence of changes in $c$ unit cell parameter ( $c$ parameter increases with increasing of ionic radius) [1]. They have shown that changes in ionic radius of cation $\mathrm{M}^{+}$reflects on the position of the vibrational modes of sulphate anions $v_{1}\left(\mathrm{SO}_{4}^{2-}\right)$ and $v_{3}\left(\mathrm{SO}_{4}^{2-}\right)$, whose wavenumber decreases with increasing parameter $c . v_{2}\left(\mathrm{SO}_{4}^{2-}\right)$ and $v_{4}\left(\mathrm{SO}_{4}^{2-}\right)$ bending modes are independent of the parameter $c$ [1]. The same authors cite similar dependence for bands position of three $\mathrm{Fe}-\mathrm{O}$ vibrational modes, which decreases with increasing of parameter c. For Fe-O bands this effect can be used only in Raman spectra, because in FTIR spectra Fe-O bands are present below $600 \mathrm{~cm}^{-1}$ that is out of detection limit of most standard FTIR detector devices $[1,3]$. Other authors, that studied the stability of the synthetic $\mathrm{Na}$-, K-and $\mathrm{NH}_{4}$-jarosite, emphasized that the highest sensitivity to different interlayer cations have positions of $v(\mathrm{OH})$ bands (e. g. $3392 \mathrm{~cm}^{-1}$ in Natrojarosite and $3434 \mathrm{~cm}^{-1}$ in Ammonium jarosite). Identification of jarosite, based on the bands wavenumber 
can be useless if the sample contains a mixture of jarosite with different cations [5].

Besides the bands wavenumber, type of jarosite can be identified using the specific bands that are present only in certain types of mineral e.g. Ammonium jarosite. In the FTIR spectrum of Ammonium jarosite characteristic bands should appear at $\sim 1420 \mathrm{~cm}^{-1}$ (H-N-H bending vibrations), 23340 and $3220 \mathrm{~cm}^{-1}$ (vibrations of ammonium ion) [1, 5, 6]. Raman spectrum bands of ammonium ion can be visible as a broad peak at $3210 \mathrm{~cm}^{-1}$ and a weak peak at $1664 \mathrm{~cm}^{-1}$, were they are assigned as internal vibrations [5].

\section{Experimental}

\subsection{Sampling}

In the present study, the waste released during zinc hydrometallurgical process known as jarosite process, was obtained from Trepca zinc smelter tailing waste in Mitrovica Industrial Park, situated in northern Kosovo. Within the sampling framework three samples of $20 \mathrm{~cm}, 1 \mathrm{~m}$ and $2 \mathrm{~m}$ depth were collected. Samples were air-dried and sieved through $2 \mathrm{~mm}$ size sieve. Raman and infrared spectroscopy were used to evaluate the characteristics of Trepca jarosite that is present in open tailing damps in Mitrovica Industrial Park. Fig. 1 (a, b and c) shows the jarosite of Trepca zinc smelter, Mitrovica, Kosovo.

\subsection{Raman spectroscopy}

Raman analyses were performed using Bruker SENTERRA Dispersive Raman spectrometer equipped with Olympus microscope. Before analysis samples are transferred on the microscope glass slide and the surface is aligned with other glass slides which were removed prior to analysis. All samples were analyzed at randomly selected points and under the same conditions $-\mathrm{Nd}$ : YAG laser operating at $532 \mathrm{~nm}$, nominal laser power $20 \mathrm{~mW}$, excitation power $2 \mathrm{~mW}$, magnification 506 , aperture $25 \times 1000$ $\mu \mathrm{m}$, spectral resolution 9-15 $\mathrm{cm}^{-1}$, grating 400a, 20 scans, $5 \mathrm{~s}$ integration time. Spectra were recorded in frequency range 10 $4000 \mathrm{~cm}^{-1}$, and as a detector, a Peltier-cooled charge coupled device (CCD) camera was used. Spectra manipulation such as baseline correction (CRC Concave Rubberband Correction) and automatic determination of peak wavenumbers (Peak Picking) was performed using OPUS 7.0 software.

\subsection{Infrared spectroscopy}

FTIR spectra were recorded on Bruker Tensor 27 FTIR spectrometer with ATR technique of the diamond cell. Spectra were collected in frequency range $600-4000 \mathrm{~cm}^{-1}$ with $10 \mathrm{scans}$ and spectral resolution $4 \mathrm{~cm}^{-1}$. In the present study we present the results of Raman and Infrared spectroscopy.

\section{Results and discussion}

FTIR spectra of samples 1, 2 and 3 in the wavenumbers range of $600-4000 \mathrm{~cm}^{-1}$ and Raman spectra in the range of 80 to $4000 \mathrm{~cm}^{-1}$

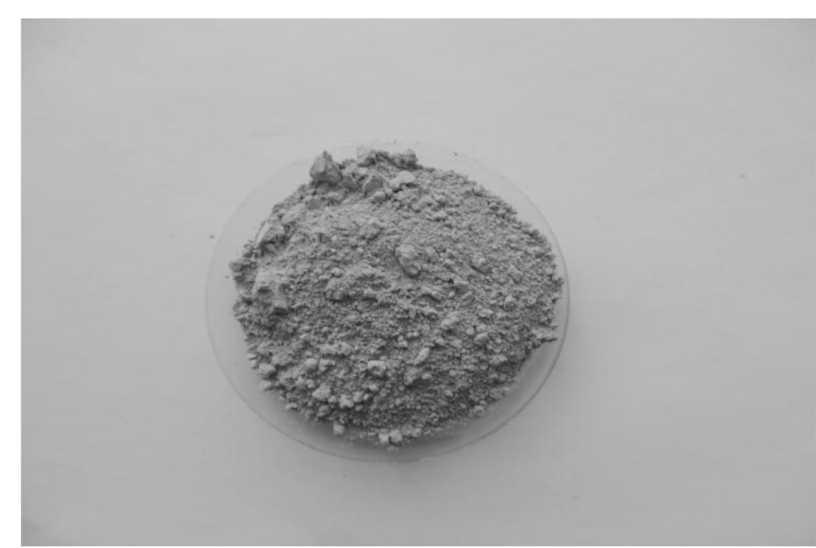

a) Sample 1

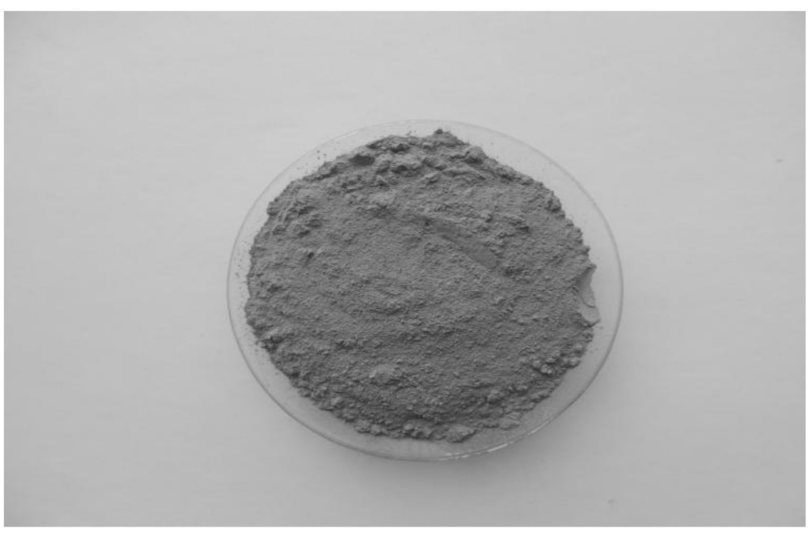

b) Sample 2

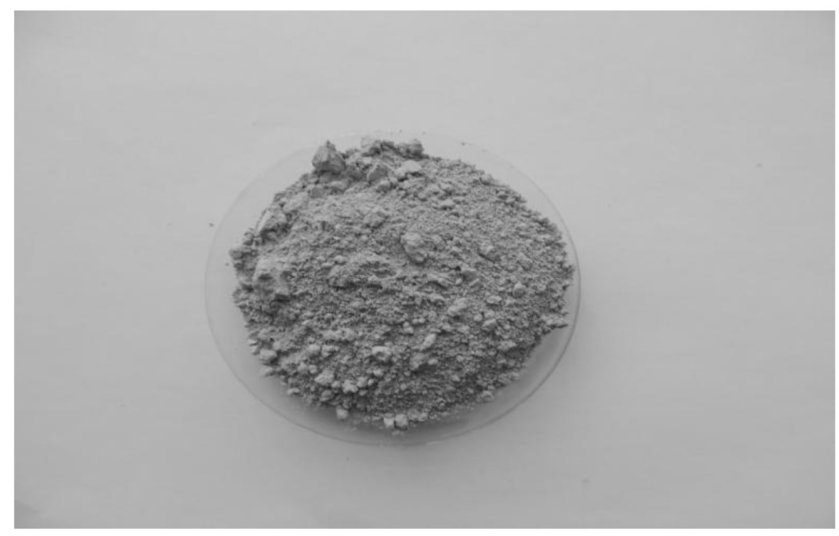

c) Sample 3

Fig. 1. Jarosite of Trepca Zinc Smelter: a) Sample 1, b) Sample 2 and c) Sample 3.

are shown in Fig. 2 and 3. Peak position and assignments are listed in Table 1. Spectra are compared with each other and bands are assigned and interpreted in accordance with the cited literature data [1-10].

FTIR spectra of samples 1, 2 and 3 do not significantly differ, Fig. 2. In spectra, at the range of $\sim 700-1300 \mathrm{~cm}^{-1}$ dominate bad 


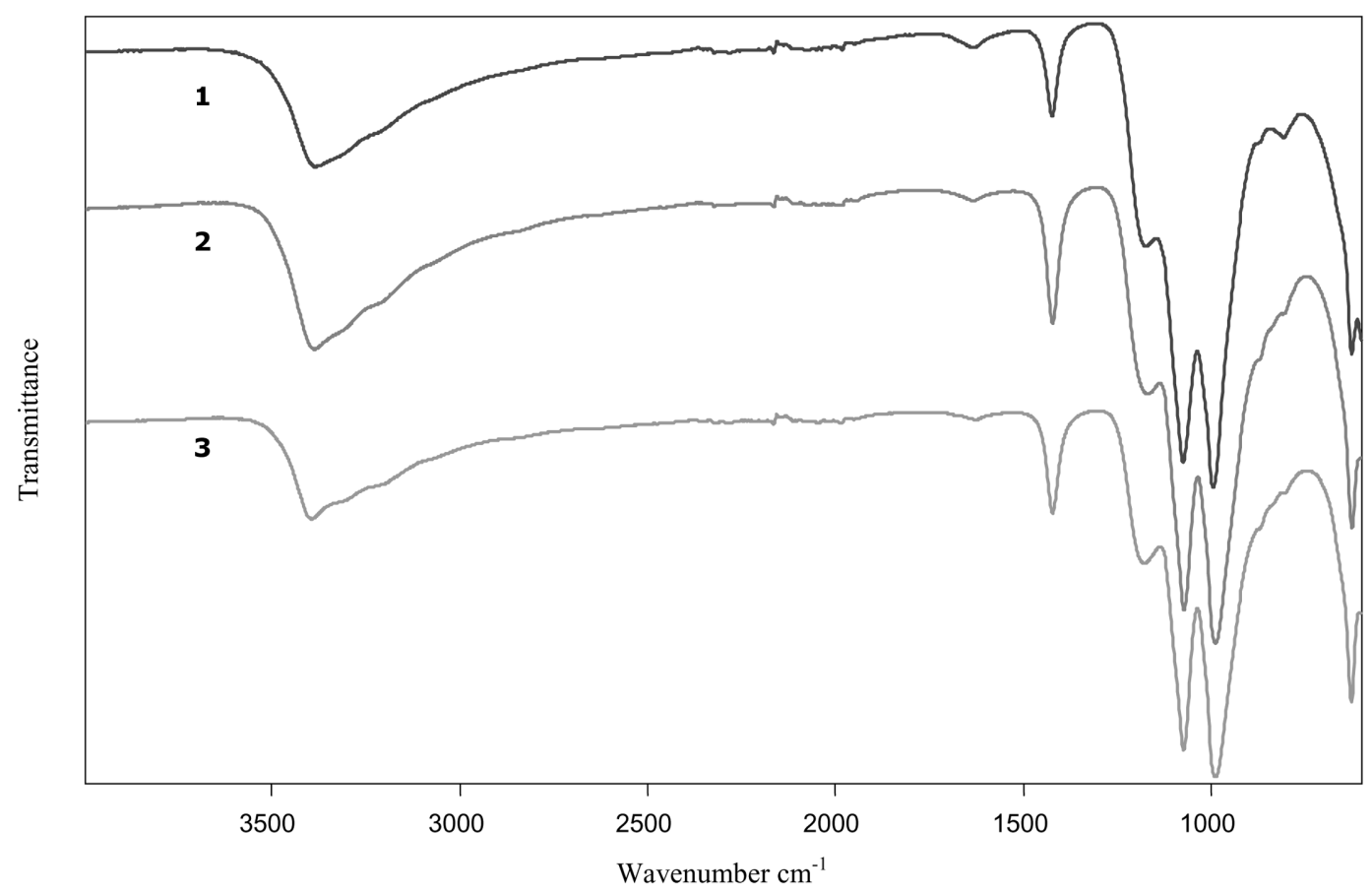

Fig. 2. FTIR spectra of Sample 1, 2 and 3 in frequency range $600-4000 \mathrm{~cm}^{-1}$.

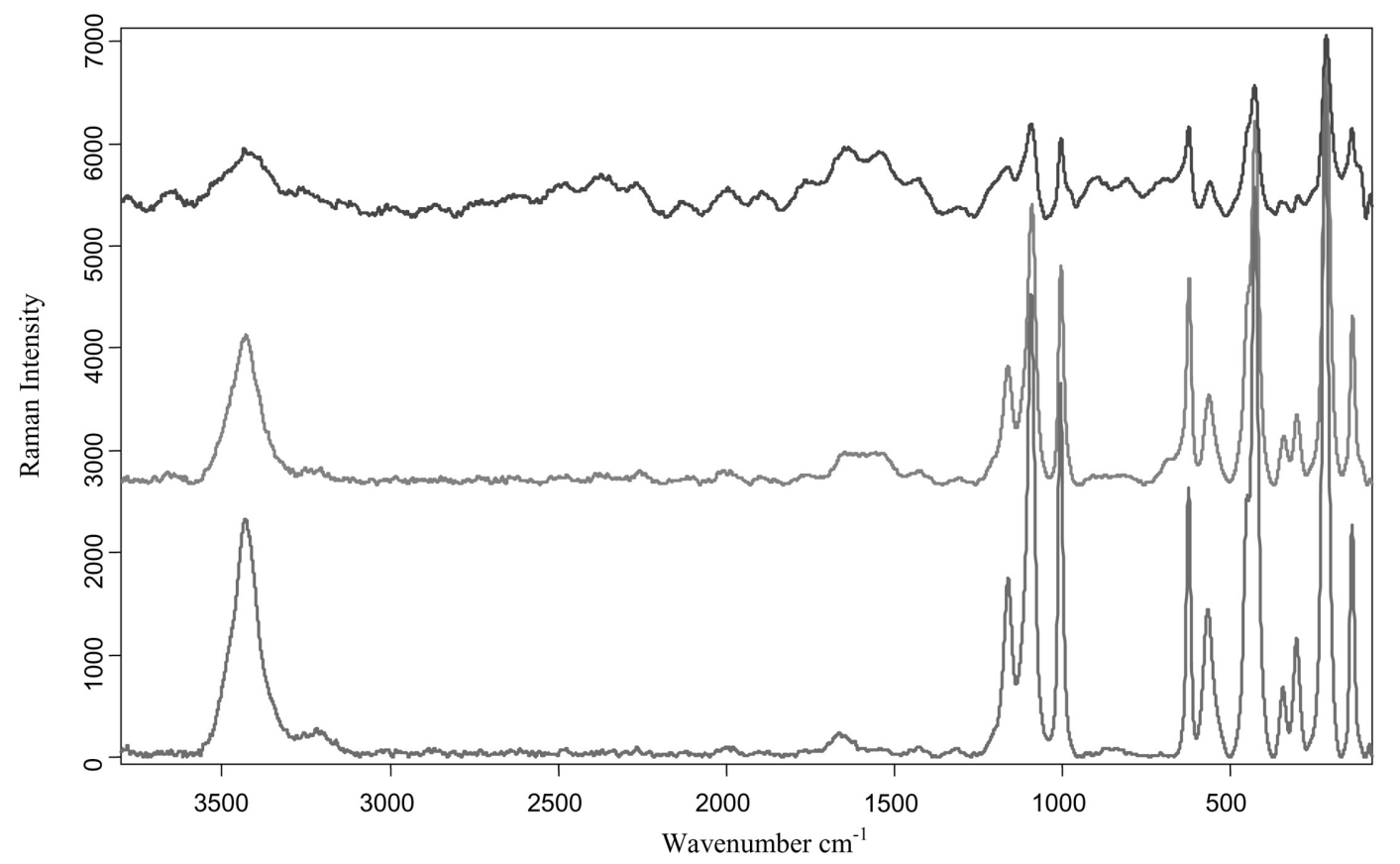

Fig. 3. Raman spectra of Sample 1, 2 and 3 in frequency range $80-3600 \mathrm{~cm}^{-1}$.

resolved bands and a broad peak in the range of higher wavenumbers $\left(2800-3600 \mathrm{~cm}^{-1}\right)$.

According to the group theory, in $\mathrm{O}-\mathrm{H}$ and $\mathrm{N}-\mathrm{H}$ stretching region, two bands that originate from $\mathrm{O}-\mathrm{H}$ stretching vibration are expected to appear. In our spectra appears only one intense but poorly resolved band in range of $3394-3386 \mathrm{~cm}^{-1}$ that is assigned as asymmetric stretching vibrations of hydroxyl, $v(\mathrm{OH})$ [6]. On the side of the lower frequencies of these bands can be observed two small shoulders at $\sim 3311$ and $\sim 3213 \mathrm{~cm}^{-1}$, Fig. 4 . Music et al. and Serna et al. reported a band at $3220 \mathrm{~cm}^{-1}$ that is assigned to the stretching mode of N-H bonds, $v\left(\mathrm{NH}_{4}\right)$, of Ammonium jarosite $[7,8]$. In that regard our band at $\sim 3213 \mathrm{~cm}^{-1}$ 
Table 1. Frequencies and assignments of infrared and Raman spectra.

\begin{tabular}{|c|c|c|c|c|c|c|c|}
\hline \multicolumn{4}{|c|}{ Infrared } & \multicolumn{4}{|c|}{ Raman } \\
\hline 1 & 2 & 3 & Assignment & 1 & 2 & 3 & Assignment \\
\hline 3386b & 3388b & $3394 b$ & $v(\mathrm{OH})$ & $3434 b$ & $3388 b$ & $3394 b$ & $v(\mathrm{OH})$ \\
\hline 3311sh & 3311sh & 3311sh & $v\left(\mathrm{NH}_{4}\right)$ & $\sim 3240 w b$ & $\sim 3240 w b$ & $\sim 3240 w b$ & $v\left(\mathrm{NH}_{4}\right)$ \\
\hline 3213sh & 3213sh & 3209sh & $v\left(\mathrm{NH}_{4}\right)$ & $\sim 1663 \mathrm{vw}$ & $\sim 1663 \mathrm{vw}$ & $\sim 1663 \mathrm{vw}$ & $v\left(\mathrm{NH}_{4}\right)$ \\
\hline $1633 w$ & $1633 w$ & $1629 w$ & $\delta\left(\mathrm{H}_{2} \mathrm{O}\right)$ & $1163 w$ & $1162 \mathrm{w}$ & $1162 w$ & $v_{3}\left(\mathrm{SO}_{4}^{2-}\right)$ \\
\hline $1423 m$ & $1421 \mathrm{~m}$ & $1421 \mathrm{~m}$ & $v\left(\mathrm{NH}_{4}\right)$ & $1093 s$ & $1091 s$ & $1093 s$ & $v_{3}\left(\mathrm{SO}_{4}^{2-}\right)$ \\
\hline $1176 w$ & $1171 w$ & $1178 w$ & $v_{3}\left(\mathrm{SO}_{4}^{2-}\right)$ & $1003 \mathrm{~s}$ & $1004 s$ & $1006 \mathrm{~s}$ & $v_{1}\left(\mathrm{SO}_{4}^{2-}\right)$ \\
\hline $1073 \mathrm{~s}$ & $1071 s$ & $1072 \mathrm{~s}$ & $v_{3}\left(\mathrm{SO}_{4}^{2-}\right)$ & $621 \mathrm{~m}$ & $623 m$ & $625 \mathrm{~m}$ & $v_{4}\left(\mathrm{SO}_{4}^{2-}\right)$ \\
\hline $994 s$ & $988 \mathrm{~s}$ & $988 \mathrm{~s}$ & $v_{1}\left(\mathrm{SO}_{4}^{2-}\right) / \mathrm{L}(\mathrm{OH})$ & $562 w$ & $564 w$ & $568 w$ & $\delta(\mathrm{Fe}-\mathrm{O}) / \gamma(\mathrm{OH})$ \\
\hline $664 \mathrm{vw}$ & 664sh & 664sh & $v_{4}\left(\mathrm{SO}_{4}^{2-}\right)$ & 450sh & 448sh & $450 \mathrm{vw}$ & $v_{2}\left(\mathrm{SO}_{4}^{2-}\right)$ \\
\hline \multirow[t]{5}{*}{$627 m$} & $625 \mathrm{~m}$ & $625 \mathrm{~m}$ & $v_{4}\left(\mathrm{SO}_{4}^{2-}\right)$ & $426 s$ & $426 s$ & $427 s$ & $v_{2}\left(\mathrm{SO}_{4}^{2-}\right) / v(\mathrm{Fe}-\mathrm{O})$ \\
\hline & & & & $343 w$ & $343 w$ & $345 w$ & $v(\mathrm{Fe}-\mathrm{O})$ \\
\hline & & & & $302 w$ & $302 w$ & $304 w$ & $v(\mathrm{Fe}-\mathrm{O})$ \\
\hline & & & & $214 v s$ & $215 v s$ & $219 v s$ & $v(\mathrm{Fe}-\mathrm{O}) / \mathrm{LV}$ \\
\hline & & & & $135 \mathrm{~m}$ & $137 m$ & $138 m$ & LV \\
\hline
\end{tabular}

b-broad, m-medium, sh-shoulder, s-strong, v-very strong, w-weak, LV-lattice vibration, L-librational
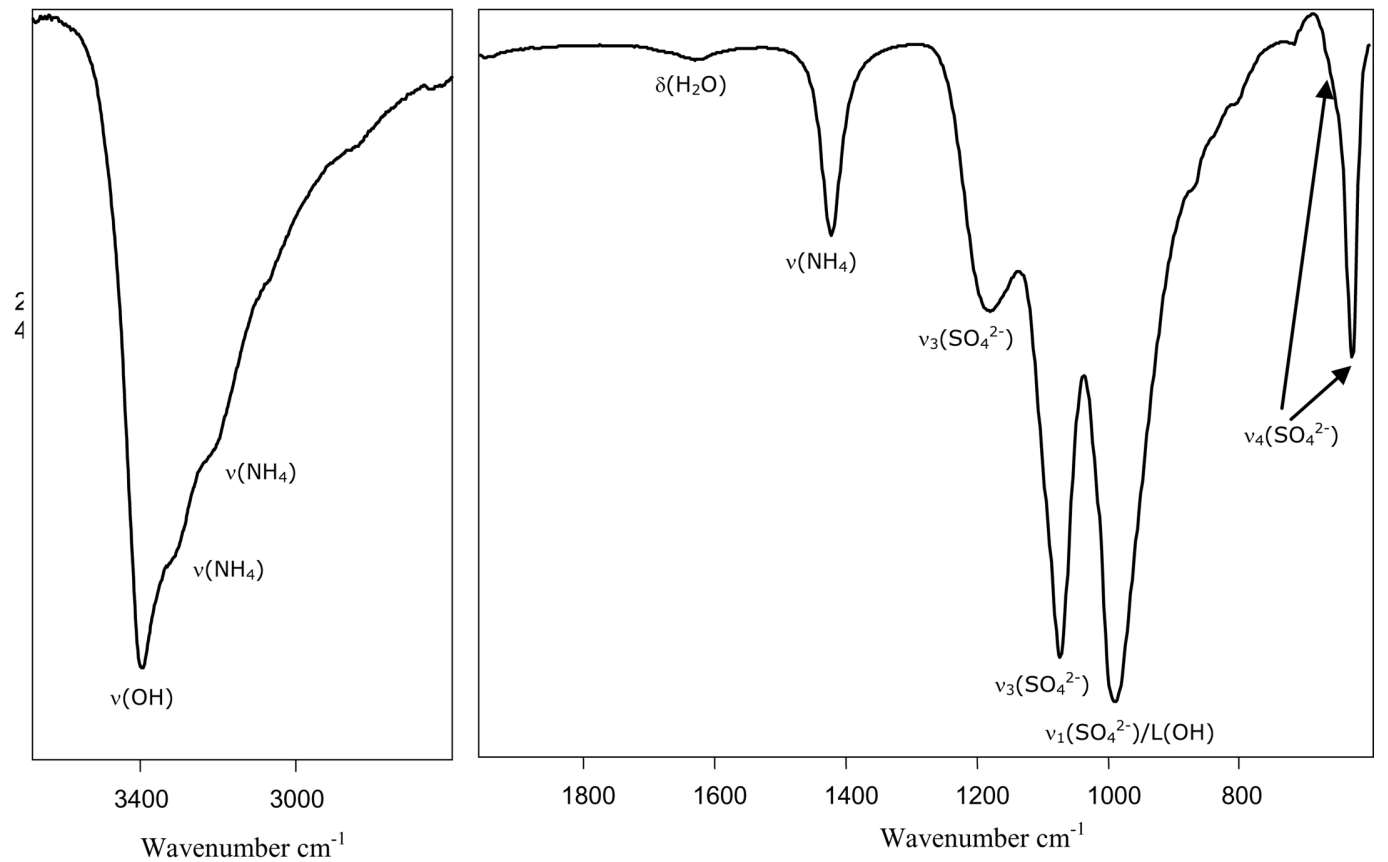

Fig. 4. FTIR spectra of Sample 3 in frequency range $3100-3600 \mathrm{~cm}^{-1}$ (left) and frequency range $600-2000 \mathrm{~cm}^{-1}$ (right).

can be assigned as $v\left(\mathrm{NH}_{4}\right)[7,8]$. The same authors also mentioned that the band at $3340 \mathrm{~cm}^{-1}$ was assigned as $v\left(\mathrm{NH}_{4}\right)$. In our spectra it could possibly be a band at $\sim 3311 \mathrm{~cm}^{-1}$. This band is less visible in spectrum 1 than in spectra 2 and 3.

A more detailed view of the spectra fingerprint area is shown in the Fig. 4. In this part of spectra is present very weak band with maximum of $\sim 1630 \mathrm{~cm}^{-1}$, which is attributed to the bending of surface adsorbed water, $\delta\left(\mathrm{H}_{2} \mathrm{O}\right)[4,9]$. Medium band at $\sim 1421$ $\mathrm{cm}^{-1}$ is attributed to bending mode of $\mathrm{N}-\mathrm{H}, v\left(\mathrm{NH}_{4}\right)$ that appears only in Ammonium jarosite. This confirms the assignment of bands at $\sim 3311$ and $3213 \mathrm{~cm}^{-1}$ [10]. In the spectrum of Ammonium jarosite, there should appear another band at $1655 \mathrm{~cm}^{-1}$, but in our study it was not observed $[7,8]$. The weak band, the center of which depends on the sample is in the range 1171$1178 \mathrm{~cm}^{-1}$, as well as the strong band at $\sim 1072 \mathrm{~cm}^{-1}$ are assigned to asymmetric stretching mode of bonds in sulphate anion, $v_{3}\left(\mathrm{SO}_{4}^{2-}\right)$. The position of these bands should indicate the type of cation $\mathrm{M}^{+}$. As above stated, the Ammonium jarosite is present in the analyzed samples 1, 2 and 3. However, the position of $v_{3}\left(\mathrm{SO}_{4}^{2-}\right)$ band that occurs in the range of $1171-1178 \mathrm{~cm}^{-1}$ shows deviation from literature values (expected at 1190-1200 $\mathrm{cm}^{-1}$ ) and actually it indicates the presence of $\mathrm{Na}^{+}$or $\mathrm{K}^{+}$cations in the structure [1, 6-8]. There is an uncertainty concerning the assignment of strong band at $994 \mathrm{~cm}^{-1}$ (Sample 1) and $988 \mathrm{~cm}^{-1}$ (Samples 2 and 3). Several authors attributed this band to symmetric stretching vibration of sulphate, $v_{1}\left(\mathrm{SO}_{4}^{2-}\right)$. Unlike them, Frost et 


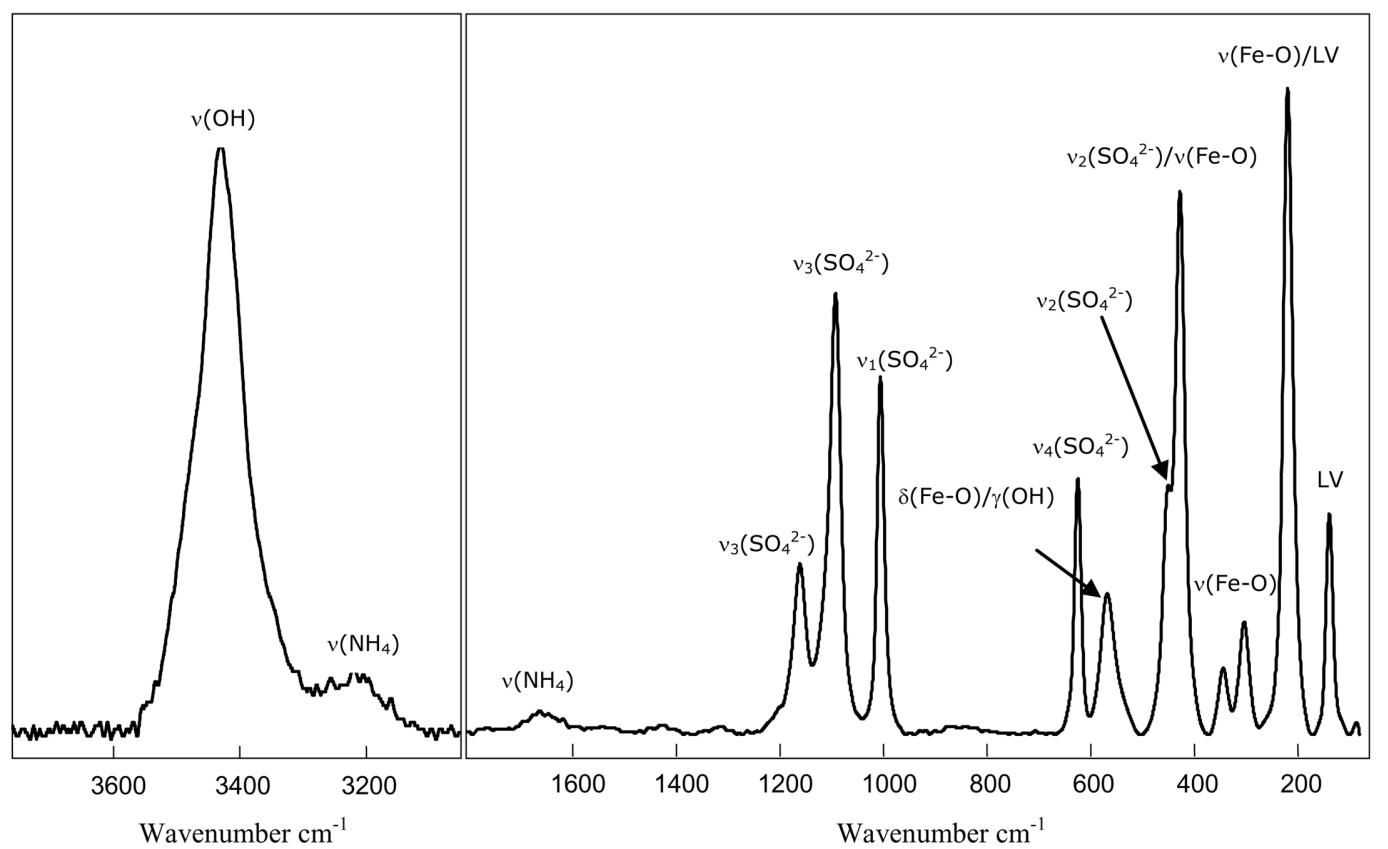

Fig. 5. Raman spectra of Sample 3 in frequency range $3000-3800 \mathrm{~cm}^{-1}$ (left) and frequency range $80-1800 \mathrm{~cm}^{-1}$ (right).

al. [6] emphasizes that the presence of such strong sulphate peak in FTIR spectrum is unusual, therefore they assigned it to the OH librational mode $[1,6,8]$. According to Frost et al. [6] sharp peak of medium intensity at $625 \mathrm{~cm}^{-1}$ is in a good agreement with the position of asymmetric sulphate group bending peak $\left(v_{4}\left(\mathrm{SO}_{4}^{2-}\right)\right)$ in Ammonium jarosite, where in the other types of jarosite is close to the position of that peak $[3-5,7,9,10]$. In fact, this sharp peak doubles with the equivalent peak at $664 \mathrm{~cm}^{-1}$ which is poorly resolved in spectrum 1 , while in spectra 2 and 3 it appears in a shoulder shape. There are some additional bands at $\sim 870$ (sh), $\sim 807(\mathrm{vw})$ and $\sim 718(\mathrm{vw}) \mathrm{cm}^{-1}$ that cannot be assigned to jarosite molecules. Therefore, they are considered as impurities present in the study material.

Sampling depth did not impact FTIR spectra of samples 1, 2 and 3, while Raman spectra show certain differences, Fig. 3. The biggest difference can be seen in sample 1 spectrum, were smaller intensity of peaks is observed, peak resolving is worse, and the base line exhibits higher noise. The differences that are stated above are most probably a result of the presence of amorphous impurities in sample 1 . In this regard, by examining the spectra one in sample 1 we can conclude that sample 1 gives the same bands as samples 2 and 3, even in similar ratios.

In all Raman spectra there are at least 5 bands that can be assigned to sulphate vibrational modes, Fig. 5. Two equivalent bands, one with low intensity at a range of $1162 \mathrm{~cm}^{-1}$ and the other band with strong intensity at a range of $1087-1093 \mathrm{~cm}^{-1}$, are assigned to the asymmetric stretching vibration of sulphate $v_{3}\left(\mathrm{SO}_{4}^{2-}\right)$. The band at $1162 \mathrm{~cm}^{-1}$ is very close to the wavenumber of Ammonium jarosite spectra according to cited references [1, $5,6]$. In addition there is a band at $1006 \mathrm{~cm}^{-1}$ that in previous works was assigned to the symmetrical stretching mode $v_{1}\left(\mathrm{SO}_{4}^{2-}\right)$ of the Ammonium jarosite molecule. Two remaining sulphate bands, $v_{4}\left(\mathrm{SO}_{4}^{2-}\right)$ and $v_{2}\left(\mathrm{SO}_{4}^{2-}\right)$, stands at the range of 625 and $450 \mathrm{~cm}^{-1}$. The last band is poorly resolved. It is visible as a shoulder on sharp and strong peak of $427 \mathrm{~cm}^{-1}$ in spectra 1 and 2 , while in spectrum 3 it forms a tiny peak on the same band. In attribution of $427 \mathrm{~cm}^{-1}$ the strong peak is questionable. Sasaki et al. [1] assigned a band to the stretching vibrations of Fe-O (at 434 $\mathrm{cm}^{-1}$ ), while the majority of other authors considered such attribution slightly possible and assigned it to the symmetric sulphate bending mode $\left(v_{2}\left(\mathrm{SO}_{4}^{2-}\right)\right)$. As it was predicted by decreasing symmetry of sulphate crystal structure, there are 6 sulphate bands in Raman spectra [1, 3, 5, 6, 10].

Remaining peaks in the spectrum are the results of Fe-O vibration, and provide peaks at 343, 302 and $215 \mathrm{~cm}^{-1}$. The first two bands have low intensity and are not fully resolved, while the last one is the most intensive ones in all spectra. Some authors assigned the $215 \mathrm{~cm}^{-1}$ band together with the $138 \mathrm{~cm}^{-1}$ band to crystal lattice vibration of the Ammonium jarosite $[5,6]$. In accordance with cited references, the band at $568 \mathrm{~cm}^{-1}$ is not assigned. The references provide two possibilities, where the bending vibration of $\delta(\mathrm{Fe}-\mathrm{O})$ is on a plane or deformation, and the other bending vibration of $\mathrm{OH}$ is out of a plane $\gamma(\mathrm{OH})[1,3-$ 6]. Chioa et al. [5] assigned that band to the liberation mode of $\mathrm{OH}$ functional group, $\mathrm{L}(\mathrm{OH})$.

There is a strong band in the high wavenumber region, in the range of $3428-3434 \mathrm{~cm}^{-1}$ that is attributed to the $v(\mathrm{OH})[3,5,10]$, Fig. 5. At low wavenumber region there is a broad and low intensity band, around $3240 \mathrm{~cm}^{-1}$ that represents inner vibrations of ammonium ion together with the low intensity band around $1663 \mathrm{~cm}^{-1}[5]$.

\section{Conclusions}

Raman and infrared spectroscopy proves to be very useful tool for the identification and characterization of the jarosite process tailing waste. The results obtained confirm the presence of 
Ammonium jarosite in three samples of Trepca tailing waste, Kosovo.

The presence of impurities in jarosite waste is detected by FTIR spectroscopy, at the range of $994 \mathrm{~cm}^{-1}$ for sample 1 and 988 $\mathrm{cm}^{-1}$ for samples 2 and 3, while the Raman spectroscopy indicates the presence of amorphous impurities in the sample 1.

The present study has also shown that the depth does not impact the FTIR spectra of samples 1, 2 and 3, while the Raman spectra show certain differences. In fact, the biggest difference is shown in the spectrum of sample 1 , were small intensity of peaks is observed. The Raman spectra showed 5 bands that are assigned to sulphate vibrational modes. Additionally, there is a strong band in the range of $3428-3434 \mathrm{~cm}^{-1}$ that is attributed to the $v(\mathrm{OH})$. From this study we can conclude that the Raman and FTIR spectral techniques found all fundamental of vibrational modes of sulphate anion, identified the type of jarosite that is present in the study material together with other impurities detected. In order to resolve the uncertainness of Raman and FTIR techniques further measurement by X-ray diffraction (XRD), SEM, as well as AAS and ICP-AES for determination of trace metals are in process.

\section{References}

[1] K. Sasaki, O. Tanaike, H. Konno, Can. Mineral. 1998, 36, 1225.

[2] G. A. Desborough, K. S. Smith, H. A. Lowers, G. A. Swayze, J. M. Hammarstrom, Sharon F. Diehl, R. W. Leinz, R. L. Driscoll, Geochim. Cosmochim. Acta. 2010, 74, 1041.

[3] R. L. Frost, R.-A. Wills, M. L. Weier, W. Martens, Spectrochim. Acta. 2006, 63, 1.

[4] P. Makreski, G. Jovanovski, S. Dimitrovska, Vib. Spectrosc. 2005, 39, 229.

[5] C. H. Chioa, S. K. Sharmab, L.-C. Ming, D. W. Muenow, Spectrochim. Acta. 2010, 75, 162.

[6] R. Frost, R.-A. Wills, T. Kloprogge, W. Martens, J. Therm. Anal. Calorim. 2006, 84, 489.

[7] S. Musić, A. Šarić, S. Popović, K. Nomura, T. Sawada, Croat. Chem. Acta. 2000, 73, 541.

[8] C. J. Serna, C. P. Cortina, J. V. G. Ramos, Spectrochim. Acta. 1986, 42, 729.

[9] J. L. Bishop, E. Murad, Am. Mineral. 2005, 90, 1100.

[10] R. L. Frost, R.-A. Wills, M. L. Weier, W. Martens, J. Raman Spectrosc. 2005, 36, 435.

Received in final form: June $18^{\text {th }} 2013$

T 172 